\title{
AN OBJECTIVE METHOD TO PRIORITIZE SOCIO-ENVIRONMENTAL WATER MANAGEMENT TRADEOFFS USING MULTI-CRITERIA DECISION ANALYSIS
}

David M. Martin ${ }^{\mathrm{a}, \mathrm{b}^{*}}$, Sue J. Powell ${ }^{\mathrm{c}}$, J. Angus Webb ${ }^{\mathrm{d}}$, Susan J. Nichols ${ }^{\mathrm{c}}$, N. LeRoy Poff ${ }^{\mathrm{a}}$

${ }^{a}$ Department of Biology and Graduate Degree Program in Ecology, Colorado State University,

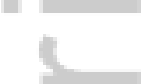
Fort Collins, Colorado, USA

${ }^{\mathrm{b}}$ U.S. Environmental Protection Agency, Office of Research and Development, Atlantic Ecology Division, Narragansett, Rhode Island, USA

${ }^{\mathrm{c}}$ Murray-Darling Basin Futures Collaborative Research Network and Institute for Applied Ecology, University of Canberra, Australia

${ }^{\mathrm{c}}$ Department of Infrastructure Engineering, The University of Melbourne, Victoria, Australia

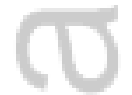

*Correspondence to: D. M. Martin, U.S. EPA Atlantic Ecology Division, Narragansett, Rhode Island, USA.

E-mail: Martin.DavidM@epa.gov

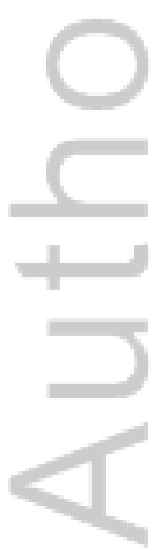

This is the author manuscript accepted for publication and has undergone full peer review but has not been through the copyediting, typesetting, pagination and proofreading process, which may lead to differences between this version and the Version of Record. Please cite this article as doi: $10.1002 /$ rra.3103

This article is protected by copyright. All rights reserved. 


\begin{abstract}
Rivers provide many social and environmental services that benefit humanity. A critical role of water mangers is to prioritize water allocation options that trade off conflicting socio-economic and hydro-ecological benefits in rivers. Methods for multi-criteria decision analysis (MCDA) provide a structured manner for researchers to aid in this process. In this paper, we describe a new MCDA method that objectively prioritizes large multi-dimensional sets of socioenvironmental tradeoffs to support well-informed water management in rivers. The method was developed based on an environmental flow planning study in the Goulburn-Broken River Catchment, Victoria, Australia. A combined simulation and heuristic optimization procedure was previously integrated into a hydrological catchment modeling network. That process resulted in a large set of viable daily water allocation schedules that traded off long-term irrigation and hydro-ecological benefits at the catchment outlet. We provided new guidance procedures to identify priority tradeoffs that can be used in stakeholder deliberations and catchment decision-making. Our MCDA method included combined multi-dimensional ordination and cluster analysis to spread the water allocation alternatives onto a two-dimensional plane to discover alternatives with similar criteria tradeoffs. A geometric distance-based method was performed on the full set of alternatives and on the identified clusters to rank the alternatives in accordance with minimizing the distance of the alternatives to an ideal but non-feasible reference point in multi-dimensional space. This method complements the use of elicitation
\end{abstract}


procedures when water manager or other stakeholder interaction is not an option or when objectivity is desired.

KEY WORDS: decision-making; environmental flows; tradeoffs; multi-criteria decision analysis

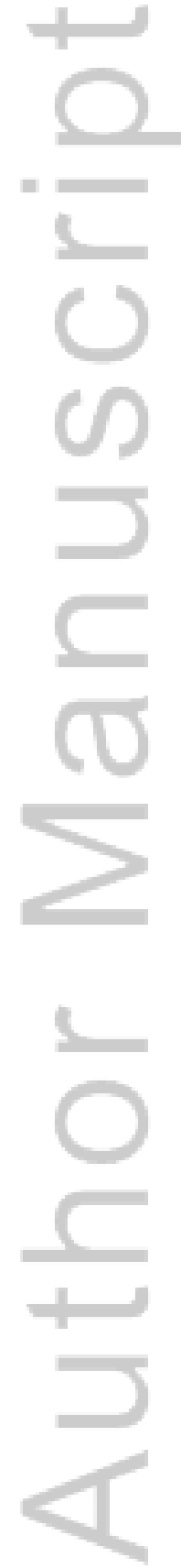

This article is protected by copyright. All rights reserved. 


\section{INTRODUCTION}

Across the globe, rivers are put into service of meeting human needs and wants (Postel and Richter, 2003). Society depends on rivers to provide important services like water supply and good water quality for domestic consumption, agriculture, industry, transportation, recreation and aesthetic enjoyment (Brauman et al., 2007). Likewise, river ecosystems transport water, sediment and nutrients, and they function to maintain adequate habitat and bio-chemical water quality to sustain instream and riparian biodiversity. Human dependence on rivers and the benefits they provide has advanced societal interests at the unanticipated cost of environmentally degrading river ecosystems (Gleick, 2003), which threatens river ecosystem function (Baron $e t$ al., 2002; Allan, 2004) and global freshwater biodiversity (Richter et al., 1998; Bunn and Arthington, 2002; Strayer and Dudgeon, 2010).

Sustainable water management in rivers requires a long-term vision to balance human and ecological freshwater needs and uncertainties in a dynamically changing environment. Applying this vision to real-world management problems exposes conflicting tradeoffs and uncertainties between the ecological needs of river ecosystems and the engineering design and operational needs of water infrastructure (Poff et al., 2015). To support a well-informed decision-making process, freshwater scientists are tasked with estimating the hydro-ecological needs of rivers using historical data and models (Poff et al., 2003), which are then integrated with socio-economic needs, constraints, and models. Clarke (2002) calls the procedure an analytical audit, which includes specifying important (i.e. outcome-oriented) and measurable 
water management criteria and incorporating them into coupled model simplifications of individual river ecosystems in an attempt to capture their spatial and temporal dynamism. Optimization techniques (Labadie, 2004; Barbour et al., 2016) are often applied, especially on large river networks with built infrastructure, to design water allocation alternatives that trade off benefits to societal criteria performance like economic return while minimizing impairment to environmental criteria like suitable species habitat.

Multi-criteria decision analysis (MCDA) is a science-based domain of research and methods that emphasizes collaborative planning and that uses systematic modeling procedures to prioritize finite sets of management alternatives with conflicting criteria and tradeoffs. The MCDA problem formulation is twofold (Belton and Stewart, 2002). First, the relative importance of the goals of the problem, which are described through criteria, are parameterized as non-dimensional scaling factors or weights. Criteria weights are viewed as quantitative representations of stakeholder preferences. Second, weighted search algorithms or rule-based heuristics are used to aggregate and rank the management alternatives based on comparing the tradeoffs in the consequences of each alternative and by incorporating measures of uncertainty to simulate imprecision of those consequences.

The domain of MCDA has long endeavored to provide suitable information from which to support well-informed management decisions. In the context of how preferences are integrated into weighted MCDA evaluations for water management in rivers, two schools of thought prevail. Preference-neutral evaluations perform weighted aggregation procedures using 
equal criteria weights (Shiau and Wu, 2006; Beilfuss and Brown, 2010). This type of evaluation aims to balance preferences among the management goals and criteria. By contrast, preferencedriven evaluations incorporate estimates of criteria weights. Criteria weights can be hypothetically based on the characteristics of a water management context (Prato, 2003; Benini et al., 2010; Wu et al., 2016), they can be simulated (Srdjevic et al., 2004), or they can be estimated through expert elicitation (Joubert et al., 2003; Bana e Costa et al., 2004; Marttunen and Hämäläinen, 2008; Martin et al., 2015). Preference-driven evaluations purposefully skew the search towards preferred management alternatives.

There are problems inherent in both schools of thought, which is why estimating the relative importance of management criteria has been regarded as a primary argument against using methods for MCDA (Gershon, 1982). Arguments against preference-neutral evaluations often emphasize that results can yield unrealistic priorities if they do not incorporate stakeholder values and information about the relative importance of management criteria. Preference-driven evaluations can yield unrealistic results if decision makers or their preferences change. We know that decision makers are naturally biased, and there are difficulties in eliciting preferences (Mareschal, 1988; Lahdelma and Salminen, 2001), including: i) elicitation methods are time consuming, ii) questions of relative importance and methods to index criteria weights are inconsistent, iii) decision makers are sometimes unreliable and/or have trouble providing straightforward answers and their answers may change over time, and iv) decision makers can be disinterested in providing explicit preference information. 
In this paper, we describe a new MCDA method to prioritize large multi-dimensional sets of socio-environmental water management tradeoffs in rivers. Our method combines ordination with cluster analysis and uses geometric distance scales to provide alternative viewpoints for decision-making in a systematic and transparent manner, without using criteria weights. We applied this method to a multi-objective optimization planning study in the Goulburn-Broken River catchment, Victoria, Australia.

\section{METHODS}

A combined ordination and clustering MCDA method moves through several distinct steps (Fig.

1). However, depending on problem characteristics like small numbers of criteria or alternatives, some of the steps may not be necessary (discussed further in CONCLUSIONS).

Multi-dimensional tradeoff table

Suppose a finite set of management alternatives $a_{i}(i=1, \ldots, n)$ each have a finite set of measurable water management criteria $c_{j}(j=1, \ldots, m)$. Each criterion is a proxy for disparate measures of river ecosystem function and socio-economic value, and the criterion performance value of a management alternative is $x_{i j}$. The $n \times m$ tradeoff table forms the basis for the MCDA method development (Fig. 1a).

\section{Ordination}

Principal component analysis (PCA) ordination is used to characterize the major variance explained in the dataset by reducing the dimensionality of the problem to one or two principal components $\left(Z_{m}\right)$ that explain the most variation in the set (Fig. 1b; APPENDIX A). PCA is 
common in the ecological sciences. However, the procedure is rarely applied in MCDA evaluations of large numbers of management alternatives like so-called non-dominated or Pareto optimal sets of alternatives that result from multi-objective optimization solvers (Reed et al., 2013; Maier et al., 2014). These datasets are unique in that moving from one alternative to the next improves at least one criterion performance value but not all.

Large numbers of alternative management tradeoffs are difficult for decision makers to consider simultaneously. The PCA reduces the dimensionality of the problem so that the tradeoff evaluation can concentrate on management alternatives that provide the greatest differences in outcomes for correlated criteria (see below). For this reason, it is important that the PCA ordination provides maximum separation of the alternatives. Stewart (1981) suggests that the dominant component $\left(Z_{1}\right)$ explain at least $90 \%$ of the variation in the alternatives so that the spread of alternatives provides a semi-rational distinction of how the alternatives deviate from one another regarding tradeoffs in the criteria performance values.

\section{Clustering}

Following the PCA, we aim to find a structure with the spread of management alternatives. This helps to discover potential tradeoffs among different groupings of the management alternatives. We use a clustering analysis of the principal component scores from the PCA (Fig. 1c). We recommend the K-means algorithm (MacQueen, 1967) because its quantitative foundation is simple, it is very common, and it can be calculated efficiently using a variety of common computer programs. The iterative K-means algorithm generates clusters such that the squared 
difference (i.e. Euclidean distance) between the empirical mean of each cluster and the points inside the cluster are minimized.

After clustering, the raw criteria performance values of the alternatives in each cluster of principle component scores are partitioned into separate datasets. In effect, there exists similarities in criteria performance in each cluster. Brans and Mareschal (2005) presumed that criteria expressing similar performance values are oriented along the PCA axes. This latent point demonstrates why PCA is an important part of the method, especially for large multidimensional sets of alternatives (e.g. non-dominated or Pareto optimal datasets); bypassing the PCA ordination and using clustering techniques from the tradeoff table may fail to provide clusters with similar criteria performance values unless the dataset is naturally correlated.

\section{Scaling and evaluation}

The next steps in this method are to perform a formal tradeoff evaluation. First, we contend that variation in criteria performance values may be large. A common currency is desired to control for that variation. We use normalized (0-1) distance measures to scale the values of the datasets so that each datum is a proportion of the highest achievable criterion value in the set (Fig. 1d). Compromise programming (Zeleny, 1973) is then performed on the full set of water management alternatives and on each cluster of alternatives using equal criteria weights to achieve a ranking of the alternatives (Fig. 1e). The graphical compromise programming method organizes large datasets with conflicting criteria tradeoffs to a priority list of alternatives that are as close as 
possible (e.g. Euclidean distance) to an "ideal" but non-feasible reference point in geometric space (coordinate 1,1,1 in Fig. 1e; APPENDIX B).

This system of methods results in several sets of ranked water management alternatives, where the highest ordered alternatives and their distinct tradeoffs may be further assessed for better-informed stakeholder deliberation and decision-making. The ranking from the full set of alternatives represent a preference-neutral viewpoint, whereas the rankings from each cluster represent implied preference information but without the use of criteria weights. The results can be assessed together for a more complete tradeoff analysis.

\section{ILLUSTRATION: GOULBURN-BROKEN CATCHMENT, VICTORIA, AUSTRALIA} The Goulburn-Broken River catchment lies within the Murray-Darling Basin, Australia (Fig. 2a). The region supports dryland and irrigated agriculture, food processing, forestry and tourism industries. Although it only makes up 2\% of the Murray-Darling Basin's land area, the catchment generates $11 \%$ of water resources for the basin. Mean annual discharge for the catchment is approximately 3,200 gigaliters (CSIRO, 2008), and approximately 50\% of the discharge is diverted to meet agricultural, stock and domestic demand.

The incorporation of flow-ecology relationships into operational decision-making for ecological water allocations (i.e. environmental flows) is a priority area of river management (Davies et al., 2014). The Goulburn-Broken River has received considerable state and federal investment in environmental flows to support improved ecological condition (e.g. Webb et al. 2015a). A proof of concept approach was previously developed that used ecological response 
models to assist with allocating environmental flows in the catchment (Powell et al., 2013). The prototype hydro-ecological predictive model used a validated quantitative response function linking the streamflow regime to the encroachment of terrestrial vegetation into the river channel (Webb et al., 2015b). This model was coded for integration into a simplified link-node water management model (Fig. 2b) provided by the Source Integrated Water Resource Modelling framework, hereafter called Source (Welsh et al., 2012). The Source model used daily discharge, rainfall and evaporation data for the period 1901 to 2012 to calibrate inflows for the link-node network and it was used to simulate ecological responses to changing environmental flow scenarios throughout the catchment.

The resulting flow-ecology response model simulates the river segment inflows, system operations, water storages, flow management, ecological response and consumptive demands within the Goulburn-Broken system, all linked to climate (see Powell et al., 2013). Although it was a proof of concept, the research was performed to provide ecologically defensible models, derived by considering available evidence from many sources, for integration into other socioeconomic river management models to support river management and policy decisions.

\section{Criteria development}

The previously calibrated hydro-ecological response model and other custom models were used with the Source model to simulate catchment inflows, system operations, environmental flows and irrigation demands based on crop water use at a range of spatial and temporal scales. First, we developed a set of rules (i.e. decision variables) to deliver 
environmental flows to suppress the encroachment of terrestrial vegetation into the river channel. These rules consider the antecedent flows, the existing terrestrial vegetation within the channel, season, and the volume of water held in storage that is available for environmental flows. Next, we developed five criteria to represent flow-ecology response (i.e. terrestrial vegetation encroachment), net irrigation benefit, and total water allocated to suppress vegetation encroachment (Table I). The irrigation criteria $C_{1}$ and $C_{2}$ were based on values extracted directly from an internal resource assessment model within Source and a calculation of annual net benefits (APPENDIX C) over the relevant irrigation nodes in the catchment network, respectively. The hydro-ecological criteria $\mathrm{C}_{3}$ and $\mathrm{C}_{4}$ were based on the previously developed flow-ecology response model and rules for the catchment. Criterion $\mathrm{C}_{5}$ was developed to minimize the total possible water allocation for environmental flows in the river system for the purpose of reducing vegetation encroachment.

\section{Optimization and tradeoff table}

A non-dominated sorting genetic algorithm NSGA-II (Deb et al., 2002) was integrated into the Source model as a dynamic simulation and heuristic optimization procedure for water allocation in the Goulburn-Broken catchment. A typical genetic algorithm is a multi-objective optimization procedure based on the development of heuristic search rules and quantitative investigations of populations of management alternatives. For the case study, the iterative procedure included Source model scenario development for daily water allocation schedules over 24 years using historic inflows and simplified climate data. The case study period (1988-2012) 
was based upon the availability of good quality gauge data. It represented a sequence of dry and wet periods in the catchment and included storage levels from Lake Eildon (Figure 2) that ranged from full to effectively empty to full again. This period of all extremes of water availability indicates that the model results may have greater general validity for potential future conditions. In the NSGA-II, an initial stochastic water allocation scenario was procured for the catchment that was intended to affect water management based on criteria goals (Table I). The initial water allocation scenario routed the responses of each criterion at relevant nodes through the catchment to a pre-defined catchment outlet and the cumulative response was recorded for each criterion. Between each scenario run, the cumulative criteria performance values at the catchment outlet were compared and the scenario run that best meets the goal was kept and recorded. The iterative process converged on 151 non-dominated tradeoff scenarios (Table II), hereafter referred to as water allocation alternatives.

The tradeoff table of water allocation alternatives is complex. Visualizing the tradeoffs in these values is a good way to summarize the complexity to decision makers. However, like many non-dominated or Pareto optimal datasets, the number of criteria and alternatives is large and difficult to interpret visually and therefore problematic to prioritize without structured decision-making methods. In response to this issue, we developed the MCDA method herein to make the decision support process more transparent for stakeholders.

Ordination and cluster analysis

This article is protected by copyright. All rights reserved. 
As described above (Fig. 1), we first applied PCA ordination to project the alternatives onto a two-dimensional plane (Fig. 3). The resulting principal component $Z_{1}$-scores provided maximum separation (93\%) of the dataset followed by $\mathrm{Z}_{2}$-scores (7\%). Upon inspection, six alternatives appeared as possible outliers (upper left alternatives in Fig. 3). Although it appears that the $7 \%$ variance on the small difference in scale along the $\mathrm{Z}_{2}$ axis may explain the distribution of the possible outliers, we took this into consideration and performed the successive steps in the MCDA evaluation with and without them to validate our results.

We performed a $\mathrm{K}$-means cluster analysis on the $\mathrm{Z}_{1^{-}}$and $\mathrm{Z}_{2}$-scores, specifying two clusters to be generated using the "cluster" package (Maechler et al., 2014) in the R programming environment. The results yielded 75 alternatives in Cluster A and 61 alternatives in Cluster B (Fig. 3).

After the clustering was performed, we inspected the raw criteria values inside each cluster and determined that Cluster A included alternatives with better irrigation criteria values for $\mathrm{C}_{1}, \mathrm{C}_{2}$, and $\mathrm{C}_{5}$, whereas Cluster $\mathrm{B}$ included alternatives with better hydro-ecological criteria values for $\mathrm{C}_{3}$ and $\mathrm{C}_{4}$. The major tradeoff among the two clusters is therefore intuitive, and we determined that a preference-neutral compromise programming evaluation of each cluster would yield rankings for decision makers with an interest in better long-term irrigation outcomes (Cluster A) and, alternatively, better hydro-ecological performance (Cluster B) throughout the catchment. Evaluation 
Compromise programming was performed on the scaled cumulative criteria performance values of the full set of water allocation alternatives and each cluster individually (Table III). An additional compromise programming iteration was performed on Cluster A without the six possible outliers described above. Yet we retained the same highest ranked results with or without those alternatives and so this additional iteration is not considered further.

The three sets of ranked alternatives provide unique viewpoints to inform the decisionmaking process. However, these preferred alternatives come with several important caveats. First, results from the full multi-dimensional dataset yield a ranking of alternatives in a preference-neutral manner. Second, the results from Cluster A analysis are viewed as preferred water allocation schedules that largely benefit irrigation in the catchment, and Cluster B results are preferred schedules that largely benefit the ecological condition of the catchment. Therefore, stakeholders who value irrigation more than ecological condition can use the highest Cluster A rankings as an appropriate set of options for water allocation in the catchment. Conversely, stakeholders who value ecological condition more than irrigation may deliberate among the tradeoffs from the Cluster B rankings.

Formal stakeholder deliberation of the tradeoffs is beyond the scope of this paper. Investigating the set of preferred water allocation alternatives would require deliberation of the exact routing schedules of water throughout the catchment and the irrigation and ecological responses at each node in the hydrologic network (Figure $2 \mathrm{~b}$ ). Socio-political values, water manager and other stakeholder intuition, and subjectivity play critical roles in that process. 
Rather, we gleaned useful information among the highest ranked alternatives in Table III and determined that deliberation among the top five ranked water allocation schedules from the full dataset evaluation and top two ranked schedules from the cluster evaluations are sufficient for well-informed water management in the catchment. We reached this conclusion because the differences in the tradeoffs of criteria values in the ranked alternatives becomes more apparent after the first several ranked alternatives are screened. This can be seen in the difference between cumulative criteria performance values in bold and non-bold alternatives in Table III. Fundamentally, we cannot say that one water allocation alternative is better than another in the sets of bold alternatives in Table III because the differences in the tradeoffs are too close.

To exemplify this determination, notice that significant changes in the tradeoffs of criteria $\mathrm{C}_{2}$ and $\mathrm{C}_{3}$ occur between the $5^{\text {th }}$ and $6^{\text {th }}$ highest ranked alternatives from the preferenceneutral iteration, and the water allocation schedules thereafter create an imbalance in the catchment relative to the highest ranked alternatives. Catchment response values for $\mathrm{C}_{2}$ changed from $55 \%$ of highest achievable to $70 \%$ and values for $\mathrm{C}_{3}$ changed from $64 \%$ to $47 \%$. The tradeoffs in criteria between alternatives remain relatively close until this break point. In Cluster $\mathrm{B}$, significant losses in the catchment performance value of criterion $\mathrm{C}_{3}$ result at a cost of significantly improving the performance of criteria $\mathrm{C}_{1}, \mathrm{C}_{2}$, and $\mathrm{C}_{5}$ between the $2^{\text {nd }}$ and $3^{\text {rd }}$ highest ranked alternatives. Consideration of the $3^{\text {rd }}$ or lower ranked alternatives in Cluster B are not useful because they begin to trade off benefits to irrigation more so than ecological condition. The tradeoffs are closer for Cluster A, but we made a similar determination. 
In summary, we reduced the large number of possible alternatives to a few small sub-sets of preferred alternatives for stakeholder deliberation in a more objective manner than by incorporating stakeholder preferences. We determined that considering alternatives further down the ranked lists was unnecessary and would constitute possible bias into the analysis.

\section{CONCLUSIONS}

Our new MCDA method objectively provides meaningful prioritizations of socioenvironmental water management tradeoffs in rivers without direct interaction with decision makers. The value of our method is demonstrated by its ability to perform seemingly subjective evaluations (i.e. prioritizing tradeoffs that favored either irrigation or hydro-ecological condition) when preference elicitation is not an option or when objectivity is desired. The method is particularly useful with large multi-dimensional datasets such as non-dominated or Pareto optimal solutions to a multi-objective optimization solver. Results may be communicated to decision makers in the same way as other methods, but with our approach, an evaluation of preferred alternatives for irrigation or ecological management of the catchment may be delivered alongside a more balanced evaluation through the described procedures.

The described method works well for the case study presented. The full method was tested on other published datasets (Martin, 2015) of socio-environmental tradeoffs (e.g. Duckstein and Opricovic, 1980; Mareschal and Brans, 1988; Chung and Lee, 2009; Hermoso et $a l ., 2015)$. Success was found where the percentage of variance explained in the ordination procedure was high enough to spread the data onto the PCA axis so that the clustering procedure 
pre-determines sets of alternatives with characteristically similar criteria performance values in the tradeoffs. Conversely, the full method is not useful for case studies with only two or three management criteria because the raw data tend to be spread appropriately. In these situations, ordination is not needed and clustering should be undertaken directly upon normalizing the criteria performance measures (see Martin et al., 2016). Specifying clusters for prioritizing management alternatives is highly subjective and dependent on stakeholders having to consider mutually contradictory sets of choices (in our case: irrigation vs. hydro-ecological benefits). Our method aims to identify characteristically similar tradeoffs in the clusters to aid decision-making, and we think that more clusters will be harder to describe and will likely complicate stakeholder deliberations.

Method development of this kind is infrequent in applications to water resource management in rivers. Yet, sustainable water management will require managers to deal with larger and more complex real-world problems and, hence, the dimensionality of future water management tradeoff designs and evaluations will grow. Describing the complex multidisciplinary tradeoffs among management criteria to water managers and decision makers will continue to be problematic because results can be unwieldy and difficult to interpret and they normally don't incorporate complementary prioritization procedures like MCDA. Stakeholders may be more hesitant to offer subjective preferences if the dimensionality and extraneous factors like space and time, river flow regime, climate change, and financial risks grow (Herman et al., 2014; Arnold et al., 2014). The dynamics of environmental change may reveal new stakeholder 
preferences and new data and may require new or revised management goals, specifications, and data into the design modeling (e.g. optimization) part of the process. Although this will likely change the results of the evaluation part of the process, it does not change the method. Our method adapts to any change in input data in a tradeoff table. It is in these areas of research and practical water management that our method is likely to prove most useful.

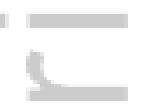

\section{ACKNOWLEDGEMENTS}

We acknowledge the assistance of the Victorian Department of Environment, Land, Water and Planning, Goulburn-Broken Catchment Management Authority, the eWater Cooperative Research Centre and the Murray-Darling Basin Futures Collaborative Research Network. DMM was supported by National Science Foundation IGERT Grant No. DGE-0966346. JAW was supported by ARC Linkage Project LP130100174. We thank one anonymous referee and the editor(s) who reviewed the manuscript.

\section{DISCLAIMER}

The research described herein was co-developed by DMM, an employee of the U.S. Environmental Protection Agency (EPA), on his own time. It was conducted independently of EPA employment and has not been subjected to the Agency's peer and administrative review. Therefore, the conclusions and opinions drawn are solely those of the authors and are not necessarily the views of the Agency.

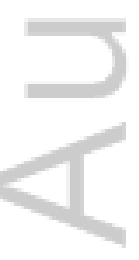

\section{REFERENCES}


Allan JD. 2004. Landscapes and riverscapes: the influence of land use on stream ecosystems. Annual Review of Ecology, Evolution, and Systematics 35: 257-284.

Arnold S, Attinger S, Frank K, Baxter P, Possingham H, Hildebrandt A. 2014. Ecosystem management along ephemeral rivers: trading off socio-economic water supply and vegetation conservation under flood regime uncertainty. River Research and Applications 32: 219-233. Bana e Costa CA, da Silva PA, Correia FN. 2004. Multicriteria evaluation of flood control measures: the case of Ribeira do Livramento. Water Resources Management 18: 263-283.

Barbour EJ, Holz L, Kuczera G, Pollino CA, Jakeman AJ, Loucks DP. 2016. Optimisation as a process for understanding and managing river ecosystems. Environmental Modelling and Software 83: 167-178.

Baron JS, Poff NL, Angermeier PL, Dahm CN, Gleick PH, Hairston NG, Jackson RB, Johnston CA, Richter BD, Steinman AD. 2002. Meeting ecological and societal needs for freshwater. Ecological Applications 12: 1247-1260.

This article is protected by copyright. All rights reserved. 
Beilfuss R, Brown C. 2010. Assessing environmental flow requirements and tradeoffs for the lower Zambezi river and delta, Mozambique. International Journal of River Basin Management 8: $127-138$.

Belton V, Stewart TJ. 2002. Multiple Criteria Decision Analysis: An Integrated Approach. Kluwer Academic Publishers, The Netherlands.

Benini L, Bandini V, Marazza D, Contin A. 2010. Assessment of land use changes through an indicator-based approach: a case study from the Lamone river basin in northern Italy. Ecological Indicators 10: 4-14.

Brans JP, Mareschal B. 2005. Promethee methods. In: Multiple Criteria Decision Analysis:

State of the Art Surveys, Figueira J, Greco S, Ehrgott M (eds). Kluwer Academic Publishers, Dordrecht, The Netherlands, pp 163-195.

Brauman KA, Daily GC, Duarte TK, Mooney HA. 2007. The nature and value of ecosystem services: an overview highlighting hydrologic services. Annual Review of Environment and Resources 32: 67-98.

This article is protected by copyright. All rights reserved. 
Bunn SE, Arthington AH. 2002. Basic principles and ecological consequences of altered flow regimes for aquatic biodiversity. Journal of Environmental Management 30: 492-507.

Chung ES, Lee KS. 2009. Prioritization of water management for sustainability using hydrologic simulation model and multicriteria decision making techniques. Journal of Environmental Management 90: 1502-1511.

Clarke MJ. 2002. Dealing with uncertainty: adaptive approaches to sustainable water management. Aquatic Conservation Marine and Freshwater Ecosystems 12: 347-363.

[CSIRO] Commonwealth Scientific and Industrial Research Organisation. 2008. Water availability in the Goulburn-Broken.

Davies PM, Naiman RJ, Warfe DM, Pettit NE, Arthington AH, Bunn SE. 2014. Flow-ecology relationships: closing the loop on effective environmental flows. Marine and Freshwater Research 65: 133-141.

Deb K, Pratap A, Agarwal S, Meyarivan T. 2002. A fast and elitist multiobjective genetic algorithm: NSGA-II. IEEE Transactions on Evolutionary Computation 6: 182-197.

This article is protected by copyright. All rights reserved. 
Duckstein L, Opricovic S. 1980. Multiobjective optimization in river basin development. Water Resources Research 16: 14-20.

Gershon M. 1982. The role of weights and scales in the application of multiobjective decision making. European Journal of Operational Research 15: 244-250.

Gleick PH. 2003. Global freshwater resources: soft-path solutions for the $21^{\text {st }}$ century. Science 302: $1524-1528$.

Herman JD, Zeff HB, Reed PM, Characklis GW. 2014. Beyond optimality: multistakeholder robustness tradeoffs for regional water portfolio planning under deep uncertainty. Water Resources Research 50: 7692-7713.

Hermoso V, Pantus F, Olley J, Linke S, Mugodo J, Lea P. 2015. Prioritising catchment rehabilitation for multi objective management: an application from SE-Queensland, Australia. Ecological Modelling 316: 168-175.

Joubert A, Stewart TJ, Eberhard R. 2003. Evaluation of water supply augmentation and water demand management options for the city of Cape Town. Journal of Multi-Criteria Decision Analysis 12: 17-25.

This article is protected by copyright. All rights reserved. 
Labadie JW. 2004. Optimal operation of multireservoir systems: state-of-the-art review. Journal of Water Resources Planning and Management 130: 93-111.

Lahdelma R, Salminen P. 2001. SMAA-2: stochastic multicriteria acceptability analysis for group decision making. Operations Research 49: 444-454.

MacQueen J. 1967. Some methods for classification and analysis of multivariate observations. In Proceedings of the Fifth Berkeley Symposium on Mathematical Statistics and Probability, Lecam L, Neyman J (eds). University of California Press, USA, pp 281-297

Maechler M et al. 2014. cluster: Cluster Analysis Basics and Extensions. R package version 1.15.2.

Maier HR, Kapelan Z, Kasprzyk J, Kollat J, Matott LS, Cunha MC, Dandy GC, Gibbs MS, Keedwell E, Marchi A, Ostfeld A, Savic D, Solomatine DP, Vrugt JA, Zecchin AC, Minsker BS, Barbour EJ, Kuczera G, Pasha F, Castelletti A, Guiliani M, Reed PM. 2014. Evolutionary algorithms and other metaheuristics in water resources: current status, research challenges and future directions. Environmental Modelling and Software 62: 271-299.

This article is protected by copyright. All rights reserved. 
Mareschal B. 1988. Weight stability intervals in multicriteria decision aid. European Journal of Operational Research 33: 54-64.

Mareschal B, Brans JP. 1988. Geometrical representations for MCDA. European Journal of Operational Research 34: 69-77.

$=$

Martin DM. 2015. Socio-environmental tradeoff analysis using decision science tools to guide river management. PhD dissertation, Colorado State University, 146 pages. (Publication No. ProQuest 3746121.)

Martin DM, Labadie JW, Poff NL. 2015. Incorporating social preferences into the ecological limits of hydrologic alteration (ELOHA): a case study in the Yampa-White River basin, Colorado. Freshwater Biology 60: 1890-1900.

Martin DM, Hermoso V, Pantus F, Olley J, Linke S, Poff NL. 2016. A proposed framework to systematically design and objectively evaluate non-dominated restoration tradeoffs for watershed planning and management. Ecological Economics 127: 146-155.

This article is protected by copyright. All rights reserved. 
Marttunen M, Hämäläinen RP. 2008. The decision analysis interview approach in the collaborative management of a large regulated water course. Journal of Environmental Management 42: 1026-1042.

Poff NL, Allen JD, Palmer MA, Hart DD, Richter BD, Arthington AH, Rogers KH, Meyers JL, Stanford JA. 2003. River flows and water wards: emerging science for environmental decision making. Frontiers in Ecology and the Environment 1: 298-306.

Poff NL, Brown CM, Grantham TE, Matthews JH, Palmer MA, Spence CM, Wilby RL, Haasnoot M, Mendoza GF, Dominique KC, Baeza A. 2015. Sustainable water management under future uncertainty with eco-engineering decision scaling. Nature Climate Change DOI:10.1038/NCLIMATE2765.

Postel S, Richter B. 2003. Rivers for Life: Managing Water for People and Nature. Island Press, Washington, D.C.

Powell SJ, Nichols SJ, Webb JA, Adams G, de Little SC, Dyack B. 2013. Optimising flow management for ecological response and consumptive use. In: MODSIM2013, $20^{\text {th }}$ International Congress on Modelling and Simulation. Modelling and Simulation Society of Australia and New

This article is protected by copyright. All rights reserved. 
Zealand, Piantadosi J, Anderssen RS, Boland J (eds).

http://www.mssanz.org.au/modsim2013/H12/powell.pdf, Accessed 15 March 2016.

Prato T. 2003. Multi-attribute evaluation of ecosystem management for the Missouri River system. Ecological Economics 45: 297-309.

$=$

a.

Reed PM, Hadka D, Herman JD, Kasprzyk JR, Kollat JB. 2013. Evolutionary multiobjective optimization in water resources: the past, present, and future. Advances in Water Resources 51: 438-456.

Richter BD, Braun DP, Mendelson MA, Master LL. 1998. Threats to imperiled freshwater fauna. Conservation Biology 11: 1081-1093.

Shiau JT, Wu FC. 2006. Compromise programming methodology for determining instream flow under multiobjective water allocation criteria. Journal of the American Water Resources Association 42: 1179-1191.

Srdjevic B, Medeiros YDP, Faria AS. 2004. An objective multi-criteria evaluation of water management scenarios. Water Resources Management 18: 35-54.

This article is protected by copyright. All rights reserved. 
Stewart TJ. 1981. A descriptive approach to multiple-criteria decision making. The Journal of the Operational Research Society 32: 45-53.

Strayer DL, Dudgeon D. 2010. Freshwater biodiversity conservation: recent progress and future challenges. Journal of the North American Benthological Society 29: 344-358.

Webb JA, de Little SC, Miller KA, Stewardson M, Rutherford ID, Sharpe AK, Poff NL. 2015 b. A general approach to predicting ecological responses to environmental flows: making best use of the literature, expert knowledge, and monitoring data. River Research and Applications 31: $505-514$.

Webb A, Vietz G, Windecker S, Hladyz S, Thompson R, Koster W, Jones M. 2015a. Monitoring and reporting on the ecological outcomes of commonwealth environmental water delivered in the lower Goulburn-Broken River and Broken Creek in 2013/14, ISBN 97807340 5112 7. Report prepared for the Commonwealth Environmental Water Office by the University of Melbourne, Melbourne, Australia.

Welsh WD, Vaze J, Dutta D, Rassam D, Rahman JM, Jolly D, Wallbrink P, Podger GM, Bethune M, Hardy MJ, Teng J, Lerat J. 2012. An integrated modelling framework for regulated river systems. Environmental Modelling \& Software 39: 81-102.

This article is protected by copyright. All rights reserved. 
Wu W, Maier HR, Dandy GC, Leonard R, Bellette K, Cuddy S, Maheepala S. 2016. Including stakeholder input in formulating and solving real-world optimization problems: generic framework and case study. Environmental Modelling and Software 79: 197-213.

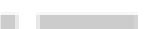

Zeleny M. 1973. Compromise programming. In: Multiple Criteria Decision Making, Cochrane J, Zeleny M (eds). University of South Carolina Press, USA, pp 262-301.

This article is protected by copyright. All rights reserved. 


\section{APPENDIX A}

\section{PRINCIPAL COMPONENT ANALYSIS}

Quantitative measures of spread used in the PCA ordination procedure include:

\section{Criterion mean:}

$$
\overline{c_{j}}=\frac{1}{n} \sum_{i=1}^{n} x_{i j}
$$

Distance between observed and mean criteria performance values:

$$
D_{i j}=x_{i j}-\overline{c_{j}}
$$

Criteria variance:

$$
\operatorname{var}(j)=\frac{1}{n-1} \sum_{j=1}^{m} D_{i j}^{2}
$$

Criteria standard deviation:

$$
\operatorname{stdv}(j)=\sqrt{\operatorname{var}(j)}
$$

\section{Criteria covariance:}

$$
\operatorname{cov}(i, j)=\frac{1}{m-1} \sum_{j=1}^{m}\left(x_{i j}-\bar{x}\right)\left(x_{i j}-\bar{x}\right)
$$

A square variance-covariance matrix $(A)$ is developed with diagonal elements equal to the sample variances of each criterion $\left(c_{j}\right)$ and off-diagonal elements equal to the sample covariance of all possible pairs of criteria performance values: 


$$
A=\left[\begin{array}{cccc}
\operatorname{var}(1) & \operatorname{cov}(1,2) & \ldots & \operatorname{cov}(1, m) \\
\operatorname{cov}(2,1) & \operatorname{var}(2) & \ldots & \operatorname{cov}(2, m) \\
\vdots & \vdots & \ddots & \vdots \\
\operatorname{cov}(n, 1) & \operatorname{cov}(n, 2) & \ldots & \operatorname{var}(m)
\end{array}\right]
$$

Eigenvalue analysis is used to estimate a vector $\vec{v}$ that satisfies $A \vec{v}=\lambda \vec{v}$, where $\vec{v}$ are the $m$ eigenvectors of matrix $A$, and $\lambda$ are the corresponding eigenvalues. The eigenvalues are associated with new variables called principal components $Z_{m}$. The principal components are used to characterize the variance explained in the raw dataset. The eigenvectors associated with each principal component are used as coefficients in linear combinations with the raw criteria performance values. Each scaled ordination value is called a $Z_{m}$-score. Development of the principal components and $Z_{m}$-scores reduces the dimensionality of the original dataset so that one or two components explain most of the variation.

The dominant eigenvalue $\lambda_{1}$ and its corresponding eigenvector $\vec{v}_{1}$ explain the most variation in the set of management alternatives. The corresponding dominant components $Z_{1}$ and $Z_{2}$ represent the highest variation in the management alternatives.

\section{APPENDIX B}

\section{COMPROMISE PROGRAMMING ALGORITHM}

Closeness is based on using the family of distance metrics $(p)$. The ideal point is equal to unity for all criteria (1) and the Euclidean distance norm is used as an appropriate distance metric ( $p=$ 2). The following problem formulation was used based on incorporating the scaled data into the calculations:

$$
\min L^{p}(i)=\sum_{j=1}^{m} w_{j}^{p}\left|1-x_{i j}\right|^{p}
$$


where $w_{j}^{p}$ is the criterion weight for criteria $j$, alternatives $i$.

\section{APPENDIX C}

\section{NET IRRIGATION BENEFIT CRITERION}

Criterion $\mathrm{C}_{2}$ was developed to maximise the average annual net benefit (I) over the combined irrigation nodes $\left(\$ \mathrm{ha}^{-1} \mathrm{yr}^{-1}\right)$. The average annual net benefit is the sum of net benefit for each crop $a$ for each year $y$, where net benefit is a function of area planted $A P$, yield $Y$, the price $P$, input costs $C$, volume of water $V$ and cost of pumping $C P$.

$$
I=\frac{\sum_{a=0}^{n \text { years }} \sum_{c=0}^{c r o p}\left[\left(A P_{a c} * Y_{c} * P_{c}\right)-\left(A P_{a c} * C_{c}\right)-\left(V_{a c} * C P\right)\right]}{n * A_{\max }}
$$

This article is protected by copyright. All rights reserved. 
Table I. List of criteria for water allocation planning in the Goulburn-Broken River catchment (Powell et al. 2013).

\begin{tabular}{lll}
\hline Criterion & Goal & Units \\
\hline $\mathrm{C}_{1}$ water extracted for irrigation & maximize & gigaliters per year $\left(\mathrm{GL} \mathrm{yr}^{-1}\right)$ \\
$\mathrm{C}_{2}$ net benefits to irrigation & maximize & \$AUS per hectare per year $\left(\$ \mathrm{ha}^{-1} \mathrm{yr}^{-1}\right)$ \\
$\mathrm{C}_{3}$ average spring terrestrial vegetation encroachment \\
$\begin{array}{l}\text { into river channel } \\
\mathrm{C}_{4} \text { maximum spring terrestrial vegetation encroachment }\end{array}$ & minimize & percent $(\%)$ \\
$\begin{array}{l}\text { into river channel (“mini-max" criterion) } \\
\begin{array}{l}\mathrm{C}_{5} \text { water allocation to suppress terrestrial vegetation } \\
\text { encroachment }\end{array}\end{array}$ & minimize & percent (\%) \\
\hline
\end{tabular}

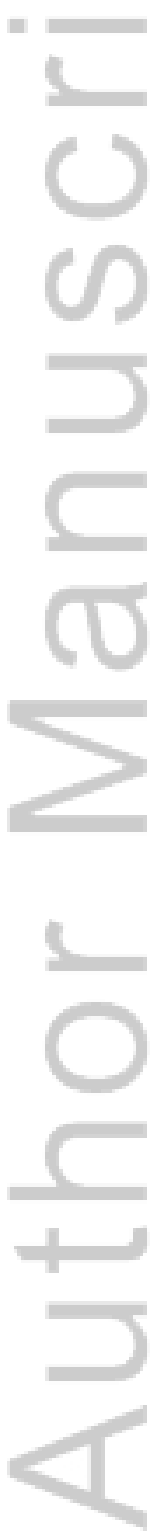


Table II. Incomplete tradeoff table of water management alternatives for the GoulburnBroken catchment. Each alternative is a different 24-year daily schedule of water allocations throughout the catchment to benefit the criteria. The cumulative criteria performance values from the catchment outlet are displayed.

\begin{tabular}{cccccc}
\hline Alternative number & $\mathrm{C}_{1}\left(\mathrm{GL} \mathrm{yr}^{-1}\right)$ & $\mathrm{C}_{2}\left(\$ \mathrm{ha}^{-1} \mathrm{yr}^{-1}\right)$ & $\mathrm{C}_{3}(\%)$ & $\mathrm{C}_{4}(\%)$ & $\mathrm{C}_{5}\left(\mathrm{GL} \mathrm{yr}^{-1}\right)$ \\
\hline 1 & 749 & 2,901 & 11 & 28.5 & 12 \\
2 & 662 & 2,704 & 2.4 & 12.6 & 283 \\
3 & 697 & 2,779 & 4.3 & 12.6 & 130 \\
4 & 749 & 2,895 & 11.1 & 28.5 & 0 \\
5 & 749 & 2,901 & 11.2 & 28.5 & 12 \\
$\ldots$ & $\ldots$ & $\ldots$ & $\ldots$ & $\ldots$ & $\ldots$ \\
151 & 731 & 2,871 & 9.2 & 19.8 & 27 \\
\hline
\end{tabular}

(2)

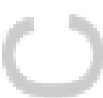

O
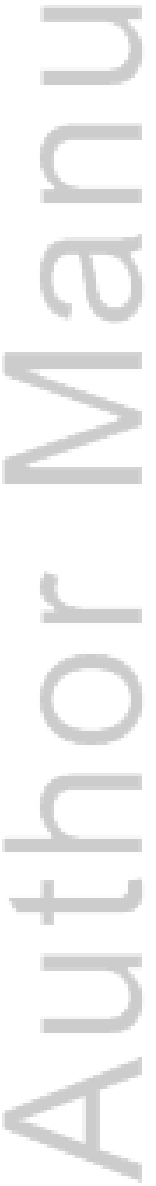

This article is protected by copyright. All rights reserved. 
Table III. Rankings from each compromise programming evaluation. The top seven ranked alternatives and their scaled criteria performance values are shown. Alternatives in bold are better options for stakeholder deliberation in each set.

\begin{tabular}{|c|c|c|c|c|c|c|c|c|c|c|c|c|}
\hline \multirow[b]{2}{*}{ Rank } & \multirow[b]{2}{*}{$\begin{array}{c}\text { Alternative } \\
\text { number }\end{array}$} & \multicolumn{4}{|c|}{ Preference-neutral } & \multirow[b]{2}{*}{$\begin{array}{c}\mathrm{C}_{5} \\
\text { Minimize } \\
\text { water } \\
\text { delivered to } \\
\text { suppress } \\
\text { TVE }\end{array}$} & \multicolumn{6}{|c|}{ Cluster A (better alternatives for irrigation) } \\
\hline & & $\begin{array}{c}\mathrm{C}_{1} \\
\text { Maximize } \\
\text { water for } \\
\text { irrigation }\end{array}$ & $\begin{array}{c}\mathrm{C}_{2} \\
\text { Maximize } \\
\text { net } \\
\text { irrigation } \\
\text { benefit }\end{array}$ & $\begin{array}{c}\mathrm{C}_{3} \\
\text { Minimize } \\
\text { average } \\
\text { springe } \\
\text { TVE }\end{array}$ & $\begin{array}{c}\mathrm{C}_{4} \text { Minimize } \\
\text { maximum } \\
\text { spring TVE }\end{array}$ & & $\begin{array}{l}\text { Alternative } \\
\text { number }\end{array}$ & $\begin{array}{c}\mathrm{C}_{1} \\
\text { Maximize } \\
\text { water for } \\
\text { irrigation }\end{array}$ & $\begin{array}{c}\mathrm{C}_{2} \\
\text { Maximize } \\
\text { net } \\
\text { irrigation } \\
\text { benefit }\end{array}$ & $\begin{array}{c}\mathrm{C}_{3} \\
\text { Minimize } \\
\text { average } \\
\text { springe } \\
\text { TVE }\end{array}$ & $\begin{array}{l}\mathrm{C}_{4} \text { Minimize } \\
\text { maximum } \\
\text { spring TVE }\end{array}$ & $\begin{array}{c}\mathrm{C}_{5} \\
\text { Minimize } \\
\text { water } \\
\text { delivered to } \\
\text { suppress } \\
\text { TVE }\end{array}$ \\
\hline 1 & 146 & 0.57 & 0.58 & 0.63 & 0.88 & 0.82 & 62 & 0.92 & 0.88 & $\mathbf{0 . 3 3}$ & 0.52 & 0.97 \\
\hline 2 & 121 & 0.57 & 0.58 & 0.61 & 0.88 & 0.83 & 56 & 0.91 & 0.88 & 0.33 & 0.51 & 0.97 \\
\hline 3 & 81 & 0.54 & 0.58 & 0.62 & 0.88 & 0.86 & 59 & 0.89 & 0.85 & 0.31 & 0.59 & 0.95 \\
\hline 4 & 92 & 0.56 & 0.55 & 0.64 & 0.88 & 0.82 & 139 & 0.93 & 0.91 & 0.27 & 0.52 & 0.95 \\
\hline 5 & 143 & 0.56 & 0.55 & 0.64 & 0.88 & 0.82 & 46 & 0.90 & 0.88 & 0.31 & 0.49 & 0.95 \\
\hline 6 & 47 & 0.58 & 0.70 & 0.47 & 0.86 & 0.82 & 132 & 0.94 & 0.94 & 0.22 & 0.52 & 0.99 \\
\hline 7 & 104 & 0.59 & 0.61 & 0.52 & 0.84 & 0.80 & 42 & 0.95 & 0.91 & 0.24 & 0.48 & 0.98 \\
\hline
\end{tabular}

Scaled values are a proportion of the highest achievable and, therefore, values closer to unity (1) are better water allocation schedules for the criterion.

Table III continued

\begin{tabular}{|c|c|c|c|c|c|c|}
\hline \multirow[b]{2}{*}{ Rank } & \multicolumn{6}{|c|}{ Cluster B (better alternatives for ecological condition) } \\
\hline & $\begin{array}{c}\text { Alternative } \\
\text { number }\end{array}$ & $\begin{array}{c}\mathrm{C}_{1} \\
\text { Maximize } \\
\text { water for } \\
\text { irrigation }\end{array}$ & $\begin{array}{c}\mathrm{C}_{2} \\
\text { Maximize } \\
\text { net } \\
\text { irrigation } \\
\text { benefit }\end{array}$ & $\begin{array}{c}\mathrm{C}_{3} \\
\text { Minimize } \\
\text { average } \\
\text { springe } \\
\text { TVE }\end{array}$ & $\begin{array}{c}\mathrm{C}_{4} \\
\text { Minimize } \\
\text { maximum } \\
\text { spring } \\
\text { TVE }\end{array}$ & $\begin{array}{c}\mathrm{C}_{5} \\
\text { Minimize } \\
\text { water } \\
\text { delivered } \\
\text { to } \\
\text { suppress } \\
\text { TVE }\end{array}$ \\
\hline 1 & 36 & 0.40 & 0.40 & 0.86 & 1.00 & 0.58 \\
\hline 2 & 3 & 0.40 & 0.40 & 0.78 & 1.00 & 0.54 \\
\hline 3 & 112 & 0.49 & 0.52 & 0.65 & 1.00 & 0.70 \\
\hline 4 & 93 & 0.45 & 0.52 & 0.66 & 0.99 & 0.57 \\
\hline 5 & 69 & 0.36 & 0.46 & 0.70 & 1.00 & 0.55 \\
\hline 6 & 85 & 0.36 & 0.34 & 0.71 & 1.00 & 0.69 \\
\hline 7 & 17 & 0.39 & 0.37 & 0.68 & 0.93 & 0.62 \\
\hline
\end{tabular}

This article is protected by copyright. All rights reserved. 
Figure 1 Conceptual diagram showing the five steps of our MCDA method, showing (a) tradeoff table, (b) statistical ordination, (c) clustering analysis, (d) re-scaling of the raw criteria performance values, and (e) evaluation using compromise programming. See text for further details.

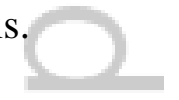

$=$

Figure 2 (a) Goulburn-Broken catchment map. (b) Simplified hydrologic network model for the catchment.

Figure 3 Principle component analysis ordination of the 151 non-dominated water management alternatives. Percent variance explained for each axis is in parentheses. Clustering analysis partitioned the alternatives into two groups that trade off conflicting irrigation and hydroecological performance.

This article is protected by copyright. All rights reserved. 


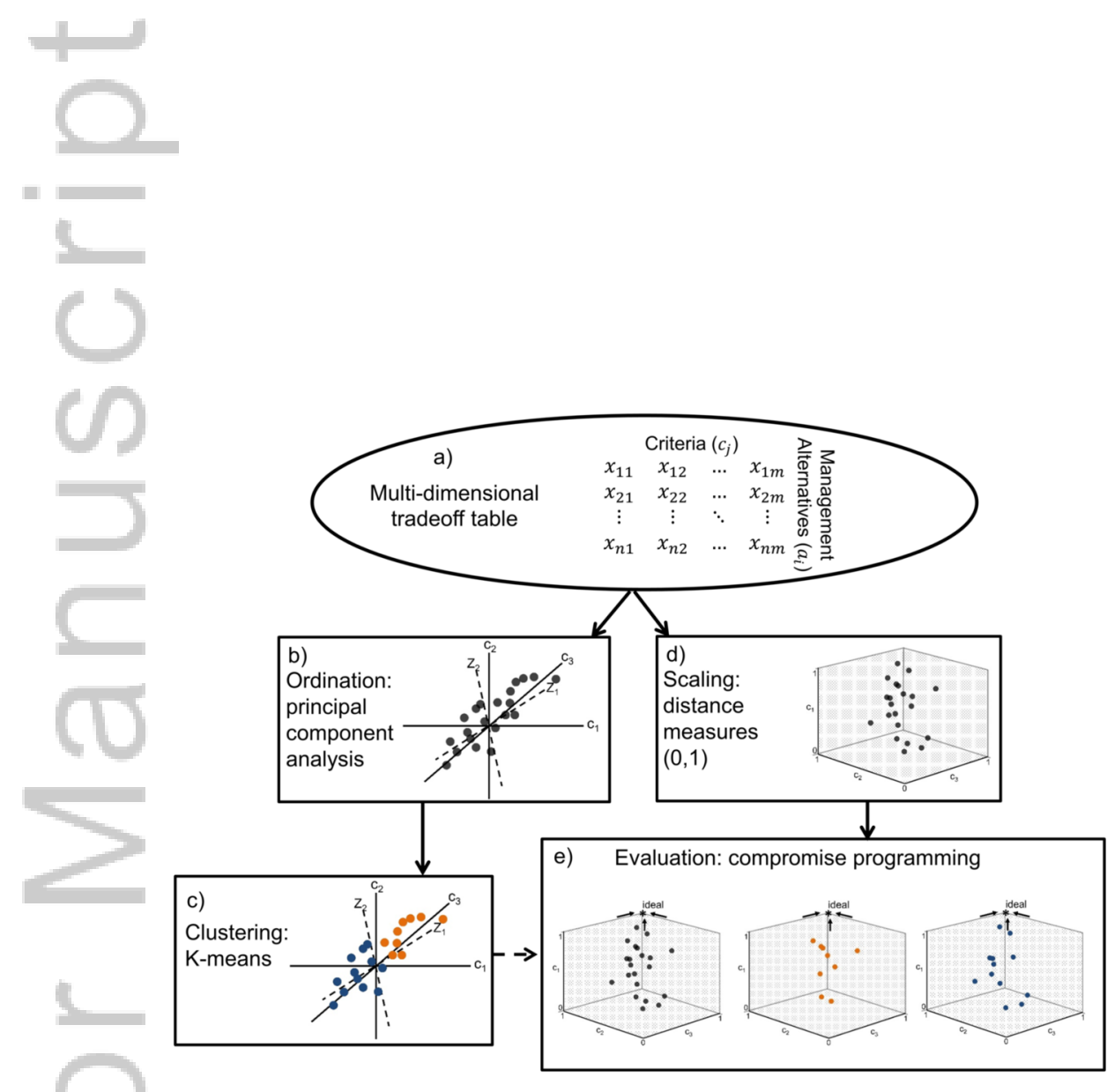

RRA_3103_F1.tif

This article is protected by copyright. All rights reserved. 


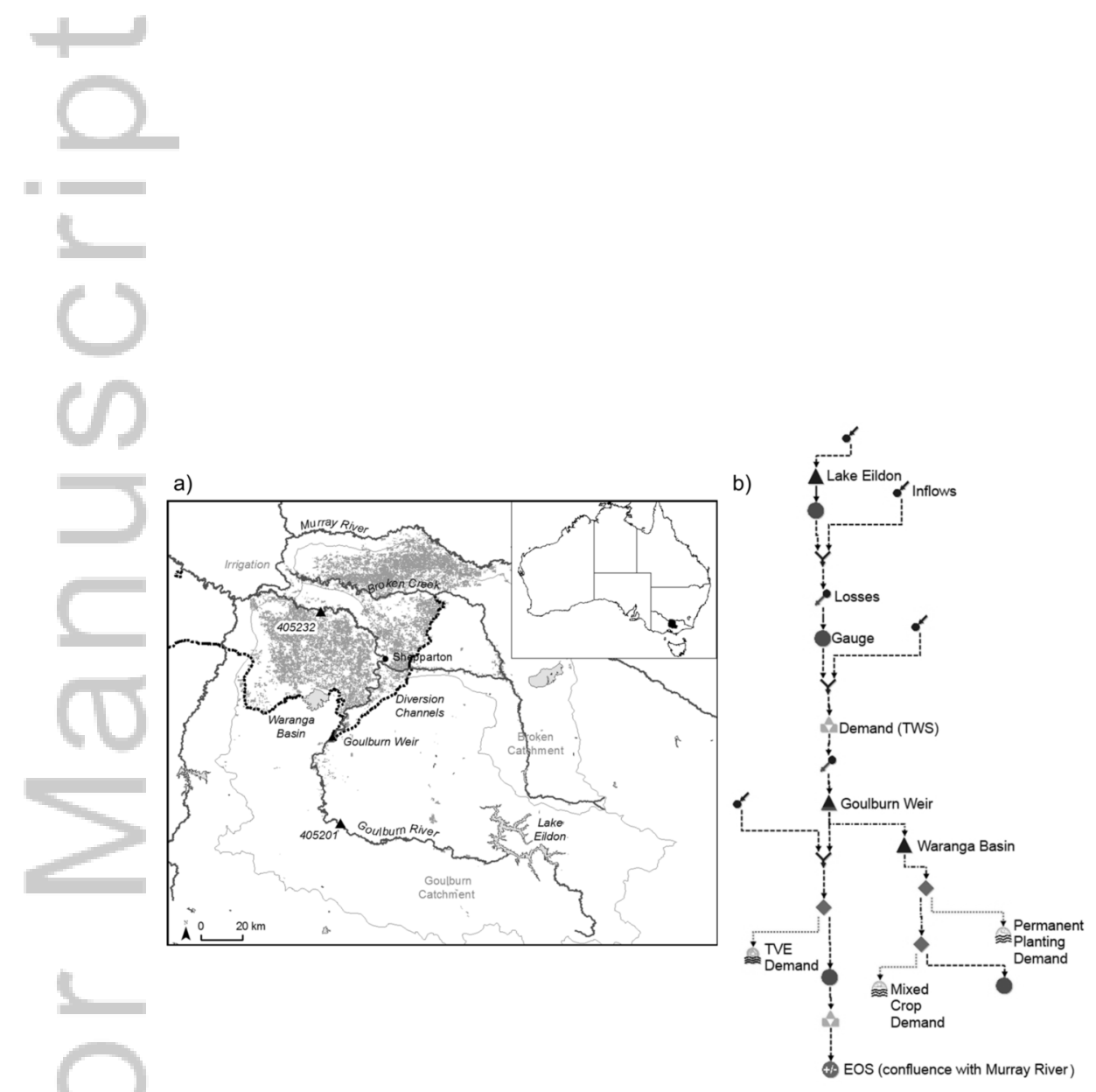

RRA_3103_F2.tif

This article is protected by copyright. All rights reserved. 


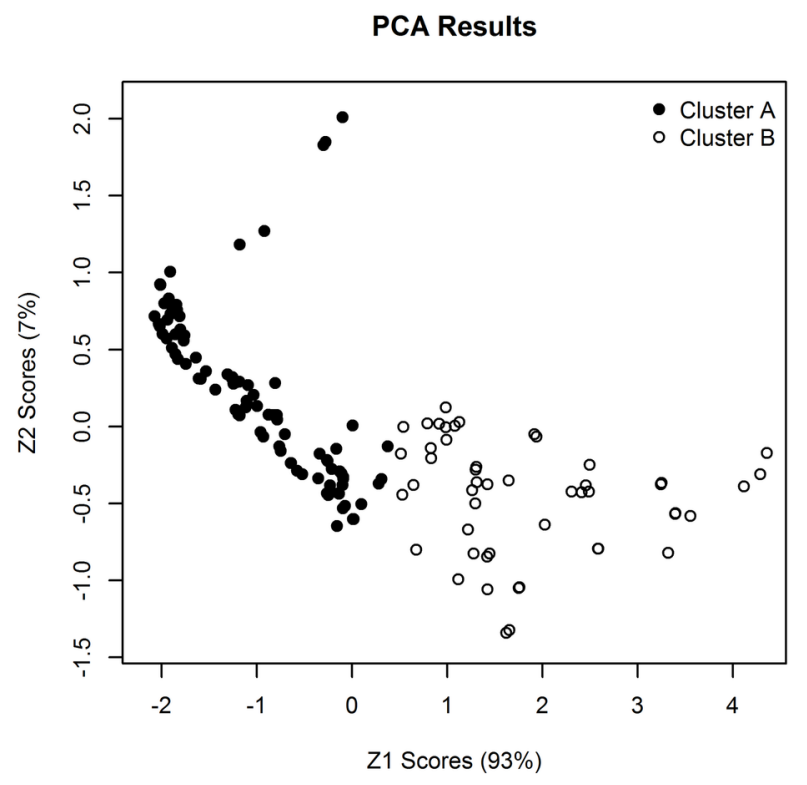

RRA_3103_F3.tiff

This article is protected by copyright. All rights reserved. 


\section{University Library}

\section{- M M N E R VA A gateway to Melbourne's research publications}

Minerva Access is the Institutional Repository of The University of Melbourne

Author/s:

Martin, DM;Powell, SJ;Webb, JA;Nichols, SJ;Poff, NL

Title:

An Objective Method to Prioritize Socio-Environmental Water Management Tradeoffs Using Multi-Criteria Decision Analysis

Date:

2017-05-01

Citation:

Martin, D. M., Powell, S. J., Webb, J. A., Nichols, S. J. \& Poff, N. L. (2017). An Objective Method to Prioritize Socio-Environmental Water Management Tradeoffs Using Multi-Criteria Decision Analysis. RIVER RESEARCH AND APPLICATIONS, 33 (4), pp.586-596. https:// doi.org/10.1002/rra.3103.

Persistent Link:

http://hdl.handle.net/11343/291814 